\title{
Relationships of depression and anxiety to readmission rates among patients with diabetes from Harare and Parirenyatwa referral hospitals in Zimbabwe
}

\author{
Prosper Chopera, Sineke Glorious Mbambo, Tonderayi Matthew Matsungo
}

Department of Nutrition, Dietetics and Food Sciences, Faculty of Science, University of Zimbabwe, P.O. Box MP167, Mt Pleasant, Harare, Zimbabwe.

\section{AuthorEmail}

SM sinekembambo@gmail.com

TMM tmatsungo@gmail.com

\section{Cell Phone}

$+263778648379$

$+263783530428$

\begin{abstract}
Background: The knowledge of determinants of readmission among individuals with diabetes minimises relapse and decreases diabetes associated morbidity and mortality.

Objectives: To explore the prevalence of depression and anxiety as well as determinants of readmission in individuals with diabetes from Harare, Zimbabwe.

Methods: A cross sectional study was carried out at Parirenyatwa and Harare group of hospitals. Participants were recruited through purposive sampling and interviewed at the diabetic clinics. Depression and anxiety were measured using the Hospital Anxiety and Depression Scale. Binary logistic regression was used to determine predictors of readmission.

Results: In total 65 participants took part, 36.9\% were males. The mean age \pm SD was $44.89 \pm 14.2$ years. Anxiety affected $40 \%$ and $20 \%$ were at risk of anxiety, while depression was reported in $27.7 \%$ and $30.8 \%$ were at risk of depression. Depression $[\mathrm{OR}=0.64,95 \% \mathrm{CI}: 0.42-0.97(\mathrm{p}=0.037)]$ and checking of blood glucose $[\mathrm{OR}=0.06,95 \% \mathrm{CI}: 0.01-0.71(\mathrm{p}=0.025)]$ were significant negative predictors of readmission among diabetic patients while anxiety was a significant positive predictor $\mathrm{OR}=1.55,95 \% \mathrm{CI}: 1.09-2.21(\mathrm{p}=0.015)$.

Conclusions: Mental health conditions in people living with diabetes are factors contributing to increased re admissions and are more prevalent with aging. Psychotherapy and education interventions are recommended for the elderly diabetic population.
\end{abstract}

Keywords: Diabetes; hospital readmission; anxiety; depression.

DOI: https://dx.doi.org/10.4314/ahs.v21i3.40

Cite as: Chopera P, Mbambo SG, Matsungo TM. Relationships of depression and anxiety to readmission rates among patients with diabetes from Harare and Parirenyatwa referral hospitals in Zimbabwe. Afri Health Sci. 2021;21(3). 1291-1300. https://dx.doi.org/10.4314/ abs. v21i3.40

\section{Introduction}

Diabetes is a complex metabolic disorder that alters the metabolism of carbohydrates, fats and proteins ${ }^{1}$. Type 2 diabetes mellitus is characterised by insulin resistance thus leading to high blood glucose. There is a paucity of nationally representative data on prevalence of type

\section{Corresponding author: \\ Prosper Chopera, \\ Department of Nutrition, Dietetics and \\ Food Sciences, Faculty of Science, University \\ of Zimbabwe, \\ P.O. Box MP167, Mt Pleasant, Harare, Zimbabwe. \\ Tel: +263773222710 \\ Email: pchopera@gmail.com}

2 diabetes in Zimbabwe. However, it is believed to have increased significantly over the past three decades from $0.4 \%$ before $1980^{2}$ to $4.6 \%$ in $2016^{3}$. In 2017 the Diabetes Association of Zimbabwe estimated that 10 in every 100 people have diabetes, and currently, diabetes statistics represent over 100000 visits or consultations at hospital outpatients departments per year ${ }^{4}$. Futhermore hospitalisation costs for diabetes complications are higher as compared to for example hospitalisation for hypertension complications over the same period ${ }^{5}$. The rise in incidence also means rise in associated co morbidities. This poses serious challenges to the provision of care and prevention of disabling comorbidities in an overburdened and underfunded healthcare setting. Similar to other chronic medical conditions, diabetes is associated with increased risk of hospital readmission ${ }^{6}$. 
Hospital readmission is an important contributor to total medical expenditures and is a rising indicator of quality of care ${ }^{5,7}$. Various supportive services should be provided on discharge to prepare the patient for transition from inpatient care to outpatient care under a continuum of a care plan. It is essential to make the plans as comprehensive as possible in terms of care, diet and medical review before discharge. The extent of preparation might determine probability of readmission though studies are still required to test efficacy of such interventions ${ }^{6}$. There are various services that can be provided to patients to prevent readmission depending on the hospital such as psychological and diet counselling ${ }^{8}$. However due to scarce resources most hospitals in developing countries will provide some diet counselling only ${ }^{9,10}$. In low-income settings, the dietician to patient ratio is high, thus compromising access to and quality of nutrition support services offered to clients.

Though improvements have been made in self-management therapies, ${ }^{11}$ there seems to be a high prevalence of hospital admissions with relapse of symptoms in Zimbabwe ${ }^{12}$. Relapse in diabetes predicts poor prognosis. It brings about deterioration in social, occupational and financial status and increases the burden of care on the family. This is particularly important in the Zimbabwean context where the deteriorating socioeconomic environment is likely to result in increased relapse with readmission among diabetic patients. Zimbabwe has experienced declining socio economic conditions ${ }^{13}$. This decline has impacted negatively on individuals with chronic conditions who rely on a steady source of income to meet their food and drug requirements ${ }^{14}$.

Knowledge of these and other determinants can enable health care providers to develop an effective care plan aimed at improving patient outcomes and prevent future readmission. This can help decrease diabetes associated mortality and improve the quality of life translating to less burden on health services. A diagnosis compounded by frequent readmission can be accompanied by feelings of futility and distress on family members but more importantly on the patient. Depression and anxiety are both mental health conditions that are highly prevalent in individuals with chronic disease such as diabetes ${ }^{15}$. They may occur at the same time and can affect self-care in such individuals. Whilst depression is a feeling of being down or upset, anxiety is a feeling of fear or worry ${ }^{15}$. This study therefore assessed the preva- lence of depression and anxiety and explored the determinants of relapse with readmission among diabetics (Type 1 and Type 2) at the two largest referral hospitals in Harare, Zimbabwe.

\section{Methods \\ Study setting and study design}

This was a cross sectional study conducted at the diabetic clinics of Parirenyatwa and Harare central hospitals in the capital city of Harare. These two major hospitals serve as national referral facilities that provide specialist and subspecialist services in Zimbabwe. Parirenyatwa is the largest (1800 bed capacity), while Harare hospital is the busiest, treating over 1200 in-patients and 900 Out-patients/casualties daily. These were convinently selected considering that in Harare, The capital city of Zimbabwe, these are the only institutions that have diabetic clinics and patient review sessions every week allowing the researchers access to the target population. The diabetic clinics at each of the hospitals enrol between 30 to 40 new participants per month.

\section{Subjects and sampling}

The study recruited clinically confirmed diabetic outpatients attending routine 'diabetic clinic'. A sample size of 89 was calculated for the study using a method described by Dean et $\mathrm{al}^{16}$ considering the following; a precision of $5 \%$, population size of $2123132{ }^{17}$, prevalence of $4.6 \%{ }^{3}$ and design effect of $1.5^{16}$. However in the current study only 65 participants could be recruited due to the low numbers attending diabetic clinic during the study period. These low numbers could have been due to an industrial action by health workers during the study period that affected total patient attendance rates in Zimbabwe's health institutions. Consenting participants included in the study were; older than 18 years of age, diagnosed with either Type 1 or Type 2 diabetis mellitus, and were conscious and well enough to converse at time of the interview. Participants were recruited as they came for the weekly 'diabetes talk' at the clinic. As they returned bi-weekly care was taken to not interview the same participant twice by using the register of the clinic.

\section{Data collection and tools}

An interview administered questionnaire with variables adapted from previous studies ${ }^{6}$ to assess diabetes self-management techniques and readmission after discharge in the last 12 months was used. The question- 
naire was divided into two sections. Part A assessed demographic and socio-economic status, while part B assessed diabetes self-management techniques, history and causes of re-admission. The following data; admission dates, diagnosis and management was confirmed using records from the patient health booklets that all chronic patients in Zimbabwe keep. Depression and anxiety were measured using the Hospital Anxiety and Depression Scale tool which had a set of questions that had scores for each response ${ }^{18}$. The scores totalled 21 for each and classification was as follows: 1 . normal $=<$ 7 points; 2 . at risk of depression $/$ anxiety $=8-11$ points; finally 3.12 and more points were either depressed or anxious. Height was measured to the last complete 1 $\mathrm{mm}$ with the participant standing erect in bare feet with head in the Frankfurt plane using a potable stadiometer (Holtain, UK) and weight (with minimal clothing) to the nearest completed $0.1 \mathrm{~kg}$, using a Tanita digital weighing scale (Dismed, USA). Body mass index (BMI) was calculated by dividing weight $(\mathrm{kg})$ by height squared (m2) and categorized using the WHO classification into: $<18.5 \mathrm{~kg} / \mathrm{m}^{2}$ (underweight), $18.5-24.9 \mathrm{~kg} / \mathrm{m}^{2}$ (normal weight), $25-29.9 \mathrm{~kg} / \mathrm{m}^{2}$ (overweight) and $\geq 30 \mathrm{~kg} / \mathrm{m}^{2}$ (obese) ${ }^{19}$.

\section{Data analysis}

The data was entered into and analysed using SPSSv 22 (IBM Inc) and Microsoft Excel 2010, statistical software. Normality of continuous variables such as age and BMI was tested using Shapiro Wilk test and confirmed visually using QQ plots due to sample size. Normality was confirmed when the level of significance of the Shapiro-Wilk Test was greater than 0.05 and data was linear on the QQ plots. Descriptive statistics were used to summarise the demographic characteristics, health characteristics, prevalence of depression and anxiety, and self-management behaviours. The Pearson Chisquare was used to examine the association between categorical variables and in cases where cell counts were below five, the Fisher's Exact test was used. Binary logistic regression was used to investigate the predictors of relapse with readmission. Conditional reverse elimination method was used to select variables, then the model with best fit was chosen. Level of significance was set at $\mathrm{p}<0.05$.

\section{Ethical consideration}

The study was conducted based on the ethical principles of respect, justice and confidentiality summarised in the 2013 Declaration of Helsinki ${ }^{20}$. Ethical approval was granted by Medical Research Council Zimbabwe (MRCZ/B/1439). Before the participants could take part in the study, verbal communication of what the study was all about was communicated to them individually and privately. Written informed consent was obtained from each participant before the interview commenced. The participants were interviewed individually and in private by a research assistant during diabetic clinic and all data was anonymised and kept confidential.

\section{Results \\ Socio-demographic characteristics of the study population}

Only 65 participants managed to take part in this study, after 8 refusals. Most of the participants were females $(63.1 \%)$ with $36.9 \%$ male. The mean age of the participants was $44.89 \pm 14.2$ years. The mean BMI of the population was $32.8 \mathrm{~kg} / \mathrm{m}^{2} \pm 28$ with $49.2 \%$ in the overweight category, $33.8 \%$ obese, $15.8 \%$ in the normal range and only $1.5 \%$ were underweight (Table 1). Those who had been readmitted were similar in most aspects to those who had never been re admitted except for whether they were on antihyperglycemic agents $(p=0.020)$, duration of time with diabetes $(p=0.014)$ (the longer the duration the more the readmissions) and source of health information $(p=0.016)$. 
Table 1: General and demographic characteristics of the study population by readmission status

\begin{tabular}{|c|c|c|c|c|}
\hline \multirow[b]{2}{*}{ Variable } & \multicolumn{3}{|c|}{ Readmission } & \multirow[b]{2}{*}{${ }^{1}$ p value } \\
\hline & $\begin{array}{l}\text { Total } \\
\text { n (\%) } \\
\text { n =65 }\end{array}$ & $\begin{array}{c}\text { Yes } \\
\text { n }(\%), \\
\text { n =41 }\end{array}$ & $\begin{array}{c}\text { No } \\
\text { n (\%), } \\
\text { n=24 }\end{array}$ & \\
\hline \multicolumn{4}{|l|}{ Gender } & 0.427 \\
\hline Female & $41(63.1)$ & $24(58.5)$ & $17(70.8)$ & \\
\hline \multicolumn{5}{|l|}{ Age } \\
\hline $18-24$ years (young adults) & $3(4.6)$ & $2(4.9)$ & $1(4.2)$ & $0.026^{*}$ \\
\hline $\begin{array}{l}25-49 \text { years (adults) } \\
\geq 50 \text { years (Elderly) }\end{array}$ & $\begin{array}{c}39(60) \\
23(35.4)\end{array}$ & $\begin{array}{l}20(48.8) \\
19(46.3)\end{array}$ & $\begin{array}{c}19(79.2) \\
4(16.7)\end{array}$ & \\
\hline \multicolumn{5}{|l|}{ Marital status } \\
\hline Never married & $16(24.6)$ & $6(14.6)$ & $10(41.7)$ & 0.062 \\
\hline Married & $29(44.6)$ & $20(48.8)$ & $9(37.5)$ & \\
\hline Separated/Divorced/Widowed & $20(30.8)$ & $15(36.6)$ & $5(20.8)$ & \\
\hline \multicolumn{5}{|l|}{ Education status } \\
\hline$\leq$ Grade 7 & $6(9.2)$ & $4(9.8)$ & $2(8.3)$ & 1.000 \\
\hline$>$ Grade 7 & $59(90.8)$ & $37(90.2)$ & $22(91.7)$ & \\
\hline \multicolumn{5}{|l|}{ Income level } \\
\hline$<$ TCPL (USD1 12) & $11(16.9)$ & $8(19.5)$ & $3(12.5)$ & 0.733 \\
\hline$>\mathrm{TCPL}$ & $54(83.1)$ & $33(80.5)$ & $21(87.5)$ & \\
\hline \multicolumn{5}{|l|}{ Nutritional status } \\
\hline Underweight & $1(1.5)$ & $1(2.5)$ & 0 & 0.513 \\
\hline Normal & $10(15.4)$ & $8(19.5)$ & $2(8.3)$ & \\
\hline Overweight & $32(49.2)$ & $20(48.8)$ & $12(50.0)$ & \\
\hline Obese & $22(33.8)$ & $12(29.3)$ & $10(41.7)$ & \\
\hline \multicolumn{5}{|l|}{ Medication } \\
\hline \multicolumn{5}{|l|}{ Frequency of taking medication } \\
\hline Adherence as prescribed & $50(76.9)$ & $32(78)$ & $18(75)$ & 0.778 \\
\hline Non Adherence & $15(23.1)$ & $9(22)$ & $6(25)$ & \\
\hline \multicolumn{5}{|l|}{ Duration of time with diabetes } \\
\hline$<5$ years & $36(54)$ & $18(43.9)$ & $18(75)$ & $0.014 *$ \\
\hline $5-10$ years & $21(32.3)$ & $15(36.6)$ & $6(25)$ & \\
\hline$>10$ years & $8(12.3)$ & $8(19.5)$ & $0(0)$ & \\
\hline \multicolumn{5}{|l|}{ Diabetes type } \\
\hline Type 2 & $57(87.7)$ & $38(92.7)$ & $24(100)$ & 0.290 \\
\hline Type 1 & $3(4.6)$ & $3(7.3)$ & $0(0)$ & \\
\hline Comorbidities & $18(27.7)$ & $13(31.7)$ & $5(20.8)$ & 0.401 \\
\hline \multicolumn{5}{|l|}{ Type of comorbidity } \\
\hline Eye disease & $14(21.5)$ & $9(22)$ & $5(20.8)$ & 0.916 \\
\hline Kidney disease & $8(12.3)$ & $4(9.8)$ & $4(16.7)$ & 0.454 \\
\hline Numbness/tingling & $8(12.3)$ & $6(14.6)$ & $2(8.3)$ & 0.372 \\
\hline Dental problems & $7(10.8)$ & $5(12.2)$ & $2(8.3)$ & 1.000 \\
\hline High cholesterol & $11(16.9)$ & $9(22.0)$ & $2(8.3)$ & 0.191 \\
\hline \multicolumn{5}{|l|}{ Source of information } \\
\hline Family & $35(53.8)$ & $17(41.5)$ & $18(75)$ & $0.016 *$ \\
\hline Co workers & $8(12.3)$ & $4(9.8)$ & $4(16.7)$ & \\
\hline Healthcare providers & $6(9.2)$ & $6(14.6)$ & $0(0.0)$ & \\
\hline Support groups & $12(18.5)$ & $10(24.4)$ & $2(8.3)$ & \\
\hline church & $4(6.2)$ & $4(9.8)$ & $0(0.0)$ & \\
\hline \multicolumn{5}{|l|}{ Communication } \\
\hline Mobile phone & $63(96.9)$ & $39(95.1)$ & $24(100)$ & 0.272 \\
\hline Access to internet & $49(75.4)$ & $30(73.2)$ & $19(79.2)$ & 0.588 \\
\hline Lifestyle behaviours & & & & \\
\hline Diet plan & 37 (56.9) & $22(53.7)$ & $15(62.5)$ & 0.487 \\
\hline Exercise & $36(55.4)$ & $22(53.7)$ & $14(58.3)$ & 0.714 \\
\hline Regular blood sugar checks & $58(89.2)$ & $38(92.7)$ & $20(83.3)$ & 0.241 \\
\hline Smocking & $11(16.9)$ & $8(19.5)$ & $3(12.5)$ & 0.733 \\
\hline Alcohol consumption & $22(33.8)$ & $13(13.7)$ & $9(37.5)$ & 0.634 \\
\hline Anxiety status & & & & \\
\hline Not anxious & $26(40)$ & $18(43.9)$ & $8(33.3)$ & 0.630 \\
\hline At risk of anxiety & $13(20)$ & $7(17.1)$ & $6(25.0)$ & \\
\hline Anxious & $26(40)$ & $16(39.0)$ & $10(41.7)$ & \\
\hline Depression status & & & & \\
\hline Not depressed & $27(41.5)$ & $15(36.6)$ & $12(50)$ & 0.180 \\
\hline At risk & $20(30.8)$ & $16(39.0)$ & $4(16.7)$ & \\
\hline
\end{tabular}


Prevalence of depression and anxiety

Table 2 summarises the prevalence of depression according to sociodemographic and other characteristics of the participants. In this study $27.7 \%$ were depressed, $30.8 \%$ at risk of depression and $41.5 \%$ not depressed. Depression was highest in the following individuals; females $(55.6 \%), 25-49$ years age group $(66.7 \%)$, individuals with postgraduate education status $(55.6 \%)$, income of between 200-500USD (61.1\%), overweight
$(50 \%)$, reliant on family support system $(55.6) \%$, with no comorbidity $(72.2 \%)$, and in those conducting regular blood sugar tests $(100 \%)$. There was however no significant difference in prevalence of depression with gender $(p=0.567)$, age $(p=0.541)$, marital status $(p=0.268)$, education status $(p=0.417)$, income level $(p=0.786), B M I(p=0.489)$, support system $(p=0.406)$, presence of comorbidity $(p=0.263)$ and regular blood sugar tests $(p=0.161)$.

Table 2: Prevalence of depression among study participants*

\begin{tabular}{|c|c|c|c|c|}
\hline & $\begin{array}{c}\text { Not } \\
\text { depressed }\end{array}$ & At risk of depression & Depressed & ${ }^{1} p$ value \\
\hline Total & $27(41.5)$ & $20(30.8)$ & $18(27.7)$ & \\
\hline \multicolumn{5}{|l|}{ Sex } \\
\hline Males & 8 (29.6) & $8(40.0)$ & $8(44.4)$ & 0.567 \\
\hline Females & $19(70.4)$ & $12(60.0)$ & $10(55.6)$ & \\
\hline \multicolumn{5}{|l|}{ Age category } \\
\hline $18-24$ years & $3(11.1)$ & $0(0.0)$ & $0(0.0)$ & 0.541 \\
\hline $25-49$ years & $15(55.6)$ & $12(60.0)$ & $12(66.7)$ & \\
\hline$\geq 50$ years & $9(33.3)$ & $8(40.0)$ & $6(33.3)$ & \\
\hline \multicolumn{5}{|l|}{ Marital status } \\
\hline Single & $9(33.3)$ & $2(10.0)$ & $5(27.8)$ & 0.268 \\
\hline Married & $11(40.7)$ & $13(65.0)$ & $5(27.8)$ & \\
\hline Separated/Divorced & $3(11.1)$ & $3(15.0)$ & $4(22.2)$ & \\
\hline Widowed & $4(14.8)$ & $2(10.0)$ & $4(22.2)$ & \\
\hline \multicolumn{5}{|l|}{ Educational status } \\
\hline Uneducated & $0(0.0)$ & $1(5.5)$ & $0(0.0)$ & 0.417 \\
\hline Primary school & $3(11.1)$ & $0(0.0)$ & $2(11.1)$ & \\
\hline Secondary school & $3(11.1)$ & $2(10.0)$ & $4(22.2)$ & \\
\hline High school & $4(14.8)$ & $6(30.0)$ & $1(5.6)$ & \\
\hline Undergraduate & $3(11.1)$ & $3(15.0)$ & $1(5.6)$ & \\
\hline Postgraduate & $14(51.9)$ & $8(40.0)$ & $10(55.6)$ & \\
\hline \multicolumn{5}{|c|}{ Income/month/person (USD) } \\
\hline Less than 200 & $5(18.5)$ & $4(20.0)$ & $2(11.1)$ & 0.786 \\
\hline $201-500$ & $18(66.7)$ & $11(55.0)$ & $11(61.1)$ & \\
\hline More than 501 & $4(14.8)$ & $5(25.0)$ & $5(27.8)$ & \\
\hline \multicolumn{5}{|l|}{ BMI } \\
\hline Underweight & $0(0.0)$ & $1(5.0)$ & $0(0.0)$ & 0.489 \\
\hline Normal & $3(11.1)$ & $2(10.0)$ & $5(27.8)$ & \\
\hline Overweight & $14(51.9)$ & $9(45.0)$ & $9(50.0)$ & \\
\hline Obese & $10(37.0)$ & $8(40.0)$ & $4(22.2)$ & \\
\hline \multicolumn{5}{|l|}{$\begin{array}{l}\text { Main support } \\
\text { system }\end{array}$} \\
\hline Family & $16(59.3)$ & $9(45.0)$ & $10(55.6)$ & 0.406 \\
\hline Co-workers & $4(14.8)$ & $2(10.0)$ & $2(11.1)$ & \\
\hline \multicolumn{5}{|l|}{ Healthcare } \\
\hline providers & $3(11.1)$ & $3(15.0)$ & $0(0.0)$ & \\
\hline Support groups & $4(14.8)$ & $5(25.0)$ & $3(16.7)$ & \\
\hline Church members & $0(0.0)$ & $1(5.0)$ & $3(16.7)$ & \\
\hline \multicolumn{5}{|c|}{ Presence of comorbidity } \\
\hline Yes & $5(18.5)$ & $8(40.0)$ & $5(27.8)$ & 0.263 \\
\hline No & $22(81.5)$ & $12(60.0)$ & $13(72.2)$ & \\
\hline \multicolumn{5}{|c|}{ Regular blood sugar checks } \\
\hline Yes & $22(81.5)$ & $18(90.0)$ & $18(100.0)$ & 0.161 \\
\hline No & $5(18.5)$ & $2(10.0)$ & $0(0.0)$ & \\
\hline
\end{tabular}


Table 3 summarises the prevalence of anxiety according to sociodemographic and other characteristics of the participants. In this study $40.0 \%$ were suffering from anxiety, $20.0 \%$ at risk and $40.0 \%$ were not suffering from anxiety. Anxiety was highest in the following; females $(53.8 \%) 25-49$ years $(57.7 \%)$, married $(34.6 \%)$, with postgraduate education (50\%), income of between 200-500USD (57.7\%), overweight (46.2\%), fam- ily support system (46.2\%), no comorbidity (65.4\%), and regular blood sugar tests $(96.2 \%)$. However there was no significant difference in anxiety levels with gender $(p=0.168)$, age category $(p=0.414)$, marital status $(\mathrm{p}=0.386)$, educational status $(\mathrm{p}=0.625)$, income level $(p=0.937)$, BMI $(p=0.933)$, support system $(p=0.244)$, presence of comorbidity $(\mathrm{p}=0.453)$ and regular blood sugar checks $(\mathrm{p}=0.391)$.

Table 3: Prevalence of anxiety among study participants*

\begin{tabular}{|c|c|c|c|c|}
\hline & Not anxious & At risk of anxiety & Anxious & ${ }^{1}$ p value \\
\hline Total & $26(40)$ & $13(20)$ & $26(40)$ & \\
\hline \multicolumn{5}{|l|}{ Sex } \\
\hline Males & $6(25)$ & $6(25)$ & $12(50)$ & \multirow[t]{2}{*}{0.168} \\
\hline Females & $20(48.8)$ & $7(17.1)$ & $14(34.1)$ & \\
\hline \multicolumn{5}{|l|}{ Age category } \\
\hline $18-24$ years & $3(100)$ & $0(0.0)$ & $0(0.0)$ & \multirow{3}{*}{0.414} \\
\hline $25-49$ years & $15(38.5)$ & $9(23.1)$ & $15(38.5)$ & \\
\hline$\geq 50$ years & $8(34.8)$ & $4(17.4)$ & $11(47.8)$ & \\
\hline \multicolumn{5}{|l|}{ Marital status } \\
\hline Single & $7(43.8)$ & $4(25.0)$ & $5(31.3)$ & \multirow[t]{4}{*}{0.386} \\
\hline Married & $13(44.8)$ & $7(24.1)$ & $9(31.0)$ & \\
\hline Seperated/Divorced & $3(30.0)$ & $0(0.0)$ & $7(70.0)$ & \\
\hline Widowed & $3(30.0)$ & $2(20.0)$ & $5(50.0)$ & \\
\hline \multicolumn{5}{|l|}{ Educational status } \\
\hline Uneducated & $0(0.0)$ & $0(0.0)$ & $1(100.0)$ & \multirow[t]{6}{*}{0.625} \\
\hline Primary school & $2(40.0)$ & $1(20.0)$ & $2(40.0)$ & \\
\hline Secondary school & $4(44.4)$ & $1(11.1)$ & $4(44.4)$ & \\
\hline High school & $4(36.4)$ & $5(45.5)$ & $2(18.2)$ & \\
\hline Undergraduate & $3(42.9)$ & $0(0.0)$ & $4(57.1)$ & \\
\hline Postgraduate & $13(40.6)$ & $6(18.8)$ & $13(40.6)$ & \\
\hline \multicolumn{5}{|c|}{ Income/month/person(USD) } \\
\hline less than 200 & $5(45.5)$ & $1(9.1)$ & $5(45.5)$ & \multirow{3}{*}{0.937} \\
\hline $200-500$ & $16(40.0)$ & $9(22.5)$ & $15(37.5)$ & \\
\hline more than 500 & $5(35.7)$ & $3(21.4)$ & $6(42.9)$ & \\
\hline \multicolumn{5}{|l|}{ BMI } \\
\hline Underweight & $1(100.0)$ & $0(0.0)$ & $0(0.0)$ & \multirow[t]{4}{*}{0.933} \\
\hline Normal & $4(40.0)$ & $1(10.0)$ & $5(50.0)$ & \\
\hline Overweight & $12(37.5)$ & $8(25.0)$ & $12(37.5)$ & \\
\hline Obese & $9(40.9)$ & $4(18.2)$ & $9(40.9)$ & \\
\hline \multicolumn{5}{|l|}{ Support system } \\
\hline Family & $13(37.1)$ & $10(28.6)$ & $12(34.3)$ & \multirow[t]{5}{*}{0.244} \\
\hline Co-workers & $4(50.0)$ & $2(25.0)$ & $2(25.0)$ & \\
\hline Healthcare providers & $4(66.7)$ & $0(0.0)$ & $2(33.3)$ & \\
\hline Support groups & $5(41.7)$ & $1(8.3)$ & $6(50.0)$ & \\
\hline Church members & $0(0.0)$ & $0(0.0)$ & $4(100.0)$ & \\
\hline \multicolumn{5}{|c|}{ Presence of comorbidity } \\
\hline Yes & $5(27.8)$ & $4(22.2)$ & $9(50.0)$ & \multirow{2}{*}{0.453} \\
\hline No & $21(44.7)$ & $9(19.1)$ & $17(36.2)$ & \\
\hline \multicolumn{5}{|c|}{ Regular blood sugar checks } \\
\hline Yes & $22(37.9)$ & $11(19.0)$ & $25(43.1)$ & \multirow{2}{*}{0.391} \\
\hline No & $4(57.1)$ & $2(28.6)$ & $1(14.3)$ & \\
\hline
\end{tabular}

\section{Predictors of relapse with readmission}

A binary logistic regression was performed to ascertain the effects of age, BMI, gender, marital status, depression, anxiety, exercise, presence of comorbidity and blood glucose check on the likelihood that participants have been readmitted (Table 4). The model explained $44.3 \%$ (Nagelkerke R2) of the variance in readmission and correctly classified $76.9 \%$ of cases. Only blood glucose self-testing, depression and anxiety were significant predictors of readmission. An increase in depres- 
sion score appears to have a protective effect against readmission in this study $\mathrm{OR}=0.64,95 \% \mathrm{CI}$ : 0.42-0.97 $(\mathrm{p}=0.037)$. This could be an indication of reluctance to seek help amongst diabetic patients suffering from depression. Self-testing was associated with a reduction in likelihood of readmission $\mathrm{OR}=0.06,95 \% \mathrm{CI}$ : 0.01 $0.71(\mathrm{p}=0.025)$. But being anxious increased likelihood of readmission $\mathrm{OR}=1.55,95 \% \mathrm{CI}: 1.09-2.21 \quad(\mathrm{p}=0.015)$.

Table 4: Predictors of relapse and readmission

\begin{tabular}{|c|c|c|c|c|c|c|c|}
\hline & \multirow[t]{2}{*}{$\mathbf{B}$} & \multirow[t]{2}{*}{ S.E. } & \multirow[t]{2}{*}{ Wald } & \multirow[t]{2}{*}{${ }^{1} p$-Value } & \multirow{2}{*}{$\begin{array}{c}\text { Odds ratio } \\
\text { (OR) }\end{array}$} & \multicolumn{2}{|c|}{ 95\% C.I for OR } \\
\hline & & & & & & Lower & Upper \\
\hline Gender (Male) & -1.04 & 0.77 & 1.82 & 0.177 & 0.36 & 0.08 & 1.60 \\
\hline Age (years) & -0.07 & 0.05 & 2.07 & 0.150 & 0.94 & 0.86 & 1.02 \\
\hline Married & -1.18 & 1.0 & 1.40 & 0.237 & 0.31 & 0.04 & 2.18 \\
\hline$<$ TCPL (USD 112) & -1.69 & 1.17 & 2.07 & 0.150 & 0.19 & 0.02 & 1.84 \\
\hline Comorbidity (Yes) & -1.06 & 0.90 & 1.38 & 0.241 & 0.35 & 0.06 & 2.03 \\
\hline $\begin{array}{l}\text { Checking blood } \\
\text { glucose (Yes) }\end{array}$ & -2.77 & 1.24 & 4.99 & $0.025^{*}$ & 0.06 & 0.01 & 0.71 \\
\hline $\begin{array}{l}\text { Exercise regularly } \\
\text { (Yes) }\end{array}$ & 0.77 & 0.78 & 0.99 & 0.321 & 2.16 & 0.47 & 9.93 \\
\hline Alcohol (Yes) & 1.54 & 0.98 & 2.47 & 0.116 & 4.66 & 0.69 & 31.78 \\
\hline Smoking (Yes) & -1.89 & 1.26 & 2.27 & 0.132 & 0.15 & 0.01 & 1.77 \\
\hline Depression score & -0.44 & 0.21 & 4.36 & $0.037^{*}$ & 0.64 & 0.42 & 0.97 \\
\hline Anxiety score & 0.44 & 0.18 & 5.872 & 0.015 & 1.549 & 1.087 & 2.206 \\
\hline Constant & 5.05 & 2.60 & 3.764 & 0.052 & 155.44 & & \\
\hline
\end{tabular}

\section{Discussion}

The aim of this study was to determine the prevalence of anxiety and depression as well as to explore the determinants of relapse with readmission in diabetic patients in Harare. We found that more than half of the participants were anxious and or at risk of anxiety. Similarly for depression, more than half were depressed and at risk of depression. Prevalences were slightly higher in females than males and as age increased. Only higher depression score and checking of blood glucose were significant negative predictors of readmission among diabetic patients while higher anxiety score was a significant positive predictor. This means being depressed and checking of blood sugar level was less likely to have one readmitted but being anxious was more likely to have one readmitted. Previous studies have found different prevalences of anxiety in diabetic populations ranging from 14\% (higher in women (55\%) versus men) ${ }^{21}$ and $40 \%$ in a Mexican population ${ }^{22}$. From literature, there is a strong association between psychological disorders and conditions like diabetes ${ }^{23}$. A systematic review and meta-analysis concluded that diabetic individuals are more likely to be diagnosed with anxiety ${ }^{24}$. Although this has been found to be true in young adults ${ }^{24}$, our current findings showed a contradictory trend where the prevalence of anxiety increased with age. Though our study did not determine causes of anxiety, studies have revealed that anxiety may stem from many factors such as complicated medical regime, monitoring of glucose levels and lifestyle changes ${ }^{25-27}$. Poor mental health outcomes have been linked to worsening metabolic control and self-management which may increase chances of readmission ${ }^{24,28,29}$. Depression seemed to have a protective effect against readmission. This may indicate a reluctance in seeking help or poor health seeking behaviour amongst diabetic individuals 
suffering from depression. In general individuals suffering from depression have been shown to have poor health seeking behaviour ${ }^{30,31}$ hence this appeared in our participants as protective from readmission. However the danger is that these may be individuals in need of health care but reluctant to seek it. While both depression and anxiety are common mental disorders their effects were different but important. We recommend larger community based studies to research on the barriers and facilitators of health seeking behaviour among individuals with diabetes and appropriately designed interventions for mental health amongst this vulnerable population.

Though anxiety and depression were more prevalent in the older age groups, age was not a predictor of readmission in the binary logistic model. These findings if replicated and proven in larger studies may glare to the need for age specific mental health interventions targeting diabetic patients. This study enrolled more women than men. We speculate that this could be as a result of the fact that females in general have higher health seeking behaviour hence more females are recruited more than males in a health facility based study ${ }^{32}$. Furthermore the 2012 national census revealed that in Zimbabwe there are generally more females $(52 \%)$ than males $(48 \%)^{33}$. Other studies have shown that age and gender are important factors influencing readmission amongst diabetic patients as well as education status, income, disease characteristics and self-management behaviours ${ }^{6,34}$. We found no such relationships in the logistic regression model probably due to the small sample size. Larger nationally representative studies examining multiple determinants are required to give more conclusive results.

In general, a high burden of diabetes management is present on a daily basis despite advancements in self-management techniques for example, home use glucometers, glucose sensors and insulin pumps. It is worrying to note that a very small percentage obtained health information from health care workers which included dieticians. More dietician led multidisciplinary anti-depression and anti-anxiety approaches are required to improve knowledge and self-management practices especially when made to be culturally appropriate $^{9,10,35}$. In addition, studies on type, form of available diabetes self-management education policies and protocols used in Zimbabwe as well as efficacy of such protocols are required.
The study had some limitations in that data was collected only at Parirenyatwa and Harare hospitals which are public hospitals. Though these are the largest referral hospitals, they did not factor in diabetic patients who attend private health care institutions. Further we did not record where these patients were referred from to these two major referral hospitals. Therefore these findings cannot be generalised. The sample size was small due to fewer patients attending the diabetic clinics at the time of study hence the results should be interpreted with caution when making inferences to wider population groups. This was mainly an exploratory study to inform development of future studies. This is crucial considering that we have grey areas on data relating to this topic in this low income context.

Apart from the limitations presented by the study, this study contributes to developing understanding of the determinants influencing hospital readmission among patients with diabetes. A comprehensive description of demographic and disease characteristics, hospital anxiety and depression, and self-management behaviours among the diabetic population was provided. As a result, the study provides a fundamental base for future studies and for clinical practice to develop intervention programmes and care plans for improving self-management behaviours or reducing anxiety and depression, which would result in reducing hospital readmission rates for patients with diabetes. We recommend further studies that incorporate larger sample sizes, patients attending private hospitals and a study design incorporating a control group to improve reliability of results.

\section{Conclusion}

The prevalence of anxiety and depression amongst diabetics was relatively high. Although anxiety plays a bigger role than depression when it comes to readmission, both are risk factors for readmission and more pronounced in older age groups. Psychosocial support is important in management of diabetes. Interventions to improve treatment of anxiety and depression are recommended particularly in older patients. Further nationally representative community based studies with larger sample sizes are warranted to give more conclusive findings on the determinants of relapse with readmission among diabetics in low income settings, private settings as well as barriers and facilitators to health seeking.

\section{Competing interests}

We declare no competing interests. 


\section{Authors contributions}

All authors participated in the conception, design, collection and data analysis. PC participated in conceptualisation and writing first draft of manuscript. SM and TM participated in writing, critical review and editing of manuscript. All authors approved final version of manuscript.

\section{Acknowledgements}

The authors would like to thank the participants as well as staff from the diabetic clinics from Harare Central Hospital and Parirenyatwa Hospital. We would like to thank Ms. M. Manyasha and Ms L. Chikoto the resident Dietitians at Harare and Parirenyatwa hospitals respectively for their assistance with data collection.

\section{References}

1. Diabetes [Internet]. [cited 2019 Oct 24]. Available from: https://www.who.int/health-topics/diabetes

2. Mutowo M, Gowda U, Mangwiro, John, Lorgelly P. Prevalence of diabetes in Zimbabwe: a systematic review with meta-analysis. Int J Public Health. 2015;60(1):1-11.

3. WHO. Zimbabwe country profile diabetes [Internet]. 2016 [cited 2020 Jun 4]. Available from: https://www. who.int/diabetes/country-profiles/zwe_en.pdf?ua $=1$

4. MOHCC. Ministry of Health and Child Care -Diabetic Association on a nationwide drive [Internet]. [cited 2020 Sep 19]. Available from: http://www.mohcc. gov.zw $/$ index.php?option $=$ com_content $\& v i e w=$ ar ticle \&id=196:diabetic-association-on-a-nationwide-drive $\&$ catid $=84 \&$ Itemid $=435$

5. Mutowo MP, Lorgelly PK, Laxy M, Renzaho AMN, Mangwiro JC, Owen AJ. The hospitalization costs of diabetes and hypertension complications in Zimbabwe: Estimations and correlations. J Diabetes Res. 2016;2016.

6. Rubin DJ. Hospital Readmission of Patients with Diabetes. Curr Diab Rep. 2018;18(4):21.

7. Axon RN, Williams M V. Hospital Readmission as an Accountability Measure. JAMA. $2011 \mathrm{Feb}$ 2;305(5):504-5.

8. Black RL, Duval C. Diabetes Discharge Planning and Transitions of Care: A Focused Review. Curr Diabetes Rev. 2019;15(2):111-7.

9. Dube L, Van Den Broucke S, Housiaux M, Dhoore W, Rendall-Mkosi K. Type 2 Diabetes Self-management Education Programs in High and Low Mortality Developing Countries: A Systematic Review. Diabetes Educ. 2015;41(1):69-85.

10. Dube L, Van den Broucke S, Dhoore W, Kalweit K, Housiaux M. An Audit of Diabetes Self-Management Education Programs in South Africa. J Public health Res. 2015 Nov 17;4(3):581.
11. Alcántara-Aragón V. Improving patient self-care using diabetes technologies. Ther Adv Endocrinol Metab. 2019;10(1-11).

12. Maradzika J, Mzorodzi T, Chikwasha V. Factors associated with hospital admissions among registered diabetes mellitus patients in Guruve and Mazowe district- Mashonaland Central Province, 2013. Int J Heal Promot Educ. 2017 Mar 4;55(2):57-65.

13. Makina D. Historical Perspective on Zimbabwe's Economic Performance: A Tale of Five Lost Decades. J Dev Soc. 2010 Mar 1;26(1):99-123.

14. Claborn DM. A Narrative Review of the Role of Economic Crisis on Health and Healthcare Infrastructure in Three Disparate National Environments. Int J Environ Res Public Health. 2020 Feb 15;17(4):1252.

15. Ironson G, Fitch C. Mental Health, Medical Illness, and Treatment with a Focus on Depression and Anxiety. In: Friedman H, editor. Encyclopedia of Mental Health. $2^{\text {nd }}$ ed. Oxford: Academic Press; 2016. p. 10718.

16. Dean A, Sullivan K, Soe M. OpenEpi: Open Source Epidemiologic Statistics for Public Health [Internet]. 2006 [cited 2020 Jun 6]. Available from: www.OpenEpi. com

17. ZIMSTAT. Provincial Report Harare Central Census Office. 2017.

18. Zigmond AS, Snaith RP. The Hospital Anxiety and Depression Scale. Acta Psychiatr Scand. 1983 Jun 1;67(6):361-70.

19. Purnell JQ. Definitions, Classification, and Epidemiology of Obesity. Endotext. MDText.com, Inc.; 2000.

20. WMA. WMA Declaration of Helsinki-Ethical principles for medical research involving human subjects. Fortaleza, Brazil: World Medical Association (WMA); 2013.

21. Grigsby AB, Anderson RJ, Freedland KE, Clouse RE, Lustman PJ. Prevalence of anxiety in adults with diabetes: A systematic review. J Psychosom Res. 2002 Dec 1;53(6):1053-60.

22. Tovilla-Zárate C, Juárez-Rojop I, Peralta Jimenez Y, Jiménez MA, Vázquez S, Bermúdez-Ocaña D, et al. Prevalence of anxiety and depression among outpatients with type 2 diabetes in the Mexican population. PLoS One. 2012/05/18. 2012;7(5):e36887-e36887.

23. Lloyd CE, Dyer PH, Barnett AH. Prevalence of symptoms of depression and anxiety in a diabetes clinic population. Diabet Med. 2000 Mar 1;17(3):198-202.

24. Smith K, Béland M, Clyde M, Gariepy G, Pagé V, Badawi $G$, et al. Association of diabetes with anxiety: A systematic review and meta-analysis. J Psychosom Res. 2013 Feb 1;74:89-99. 
25. Polonsky WH, Anderson BJ, Lohrer PA, Welch G, Jacobson AM, Aponte JE, et al. Assessment of diabetes-related distress. Diabetes Care. 1995;18(6):754-60.

26. Surwit RS, Schneider MS, Feinglos MN. Stress and diabetes mellitus. Diabetes Care. 1992;15(10):1413-22.

27. Ciechanowski PS, Katon WJ, Russo JE. Depression and diabetes: Impact of depressive symptoms on adherence, function, and costs. Arch Intern Med. $2000 \mathrm{Nov}$ 27;160(21):3278-85.

28. Misra R, Lager J. Predictors of quality of life among adults with type 2 diabetes mellitus. J Diabetes Complications. 2008;22(3):217-23.

29. Jing X, Chen J, Dong Y, Han D, Zhao H, Wang X, et al. Related factors of quality of life of type 2 diabetes patients: a systematic review and meta-analysis. Health Qual Life Outcomes. 2018;16(1):189.

30. Magaard JL, Seeralan T, Schulz H, Brütt AL. Factors associated with help-seeking behaviour among individuals with major depression: A systematic review. PLoS One. 2017 May 11;12(5):e0176730.
31. Kohn R, Saxena S, Levav I, Saraceno B. The treatment gap in mental health care. Bull World Health Organ. 2004/12/14. 2004 Nov;82(11):858-66.

32. Thompson AE, Anisimowicz Y, Miedema B, Hogg W, Wodchis WP, Aubrey-Bassler K. The influence of gender and other patient characteristics on health care-seeking behaviour: a QUALICOPC study. BMC Fam Pract. 2016 Mar 31;17:38.

33. ZIMSTAT. Population Census Results. Final Report. Harare, Zimbabwe; 2013.

34. Robbins TD, Lim Choi Keung SN, Sankar S, Randeva H, Arvanitis TN. Risk factors for readmission of inpatients with diabetes: A systematic review. J Diabetes Complications. 2019 May 1;33(5):398-405.

35. Nkomani S, Ruskaniko S, Blaauw R. The impact of existing diabetes self-management education interventions on knowledge, attitudes and practices in public health care institutions in Harare, Zimbabwe. South African J Clin Nutr. 2019 Jul 25;1-7. 